the subsequent rise must not be lost sight of in cases which show extensive cavitation, and in which there is a possible danger of rupture of the cavity.

No attempt has been made to explain or correlate the reasons for the alterations of pressures, but it is obvious that the weight of the heart, the abdominal support of the diaphragm, and the increased action of the opposite lung all play a part. That the alteration does talse place is sufficient to warrant attention.

\section{A CASE OF MEGACOLON.}

\author{
BY
}

E. R. FLINT, F.R.C.S. SURGICAL TUTOR, GENERAL INFIRMARY, LEEDS.

The following case presents many points of interest; amongst others, the colon was the largest of which I have seen any record.

A man, aged 32, was admitted to the Leeds General Infirmary in Augut, 1918, for distension of the abdomen and faecal incontinence. August, 1918, for distensich on operation was performed some twenty-four hours after birth. The rectum was opened at a depth of $3 / 4 \mathrm{in}$. from the perineum and the edges stitched to the skin. The subsequent history was one of continual trouble with the bowels. He never had his borvels moved withoüt aperients or enemata, and even these did not prevent him having attacks of partial obstruction, for which he was, on several occasions, readmitted to the infirmary and relieved by vigorous treatment with enemata After such relief he returned home gradually to fill up again, and so on. Vomiting and pain wer quite exceptional. His complaint was, as on this occasion, of enormous distension and difficulty with the bowels, and when thi was at its worst he would get a form of diarrhoea with incontiuence. He worked fitfully, having often to absent himself for treatment, and when at work he had constantly to be attending to himself.

On admission, in August, 1918 , the abdomen was enormous, like that of a woman with the largest imaginable ovarian cyst; the parjetes were tense, and had a glazed appearance. There was no visible peristalsis and no evidence of distinct coils. He was in no real distress except from the contiuuous oozing away of faeces. The rectum was found to be full of great hard masses of faecal rectum was found to be full of great hard masses of faecal material, and, though the anal margin felt rigid with scar tissue, him. I thought the condition was one of interference with colcn action, as one sees in Hirschsprung's disease, but complicated by the possible interference with control of defaecation, owing to the anal condition.

I decided, therefore, to do a colectomy, but to empty the bowel to some degree in the first place by colostomy. In this, however. to some degree in the first place by colostomy. In this, however, the colostomy it was impossible to create a spur owing to the enormous $s$ ze of the colou, and the opening very soon began to close. Consequently in November I removed the sigmoid and upper part of the rectum, together with the colostomy opening. The sigmoid was enormous, the two limbs being the size of an average male thigh, and the apex of the loop was beneath the liver. The wall was markedly hypertrophied. The same condition extended down into the rectum in its whole length, but above it ended almost abruptly at the lower end of the descending colon. ended almost abruptly at the lower end of the descending colou. Proximal to this point

I brought the cut end of the descending colon to the surface to act as a permanent colostomy, and stitched up the upper end of the rectum, which was about 6 in. across. In the ordinary way I might have tried stitching the two ends together, but owing to the suspicion under which the anal canal lay I decided the best interests of the patient would be served by a permanent colostomy.

I have seen the man frequently since, and he says he has never felt better in his life; he has lost all the features of autointoxica tion which were so marked before, and he has been at work continuously since. He has no inconvenience from the colostomy, for by careful dieting he can easily regulate his bowels so that the act once a day, and at.a time when it is convenient for him to attend to them. Immediately after thie operation considerable difficulty was experienced in evacuating the rectum; now he has no trouble with this at all.

The segment of bowel removed was $2 \mathrm{ft}$. $6 \frac{1}{2} \mathrm{in}$. long, 22 inches in circumference, and weighed $111 \mathrm{~b}$.

I have labelled this as a case of megacolon because I am not sure whether it should be classed as a case of Hirschsprung's disease, or as one of obstruction due to the scarring resulting from the operation for the imperforate anus. There has never been auything which one could call an obstruction at the anus since I lrave seen him, though, of course, the natural elasticity of the part was absent, and I could not satisfy myself of the presence of a sphincter. On the other hand, apart from the anus, the pathological appearances were exactly those of Hirschsprung's disease, and the existence of the condition from birth conforms to either alternative.

\section{GASTRO-ENTEROSTOMY, AND SOME DIETETIC RULES.}

BY

SIR JOHN O'CONOR, K.B.E., M.A., M.D.,

SENIOR MEDICAL OFFICER, BRITISH HOSPITAL, BOENOS AIRES.

As a confirmed gastro-enterostomist of some years' standing, I wish to express admiration for Mr. Paterson's lucid exposition; at a recent rneeting of the Royal Society of Medicine, of the rationale of this operation, and my personal experience justifies the statement that this gentleman's verdict fits the bill as to the application and success of the procedure.

Also, I was deeply interested in reading Mr. Walton's dark roll of surgical iniquity, which I am sure will command pro. found study by all who are responsible for the efficient training of surgeons. At the same time, I do not wish to infor that, although I happened to escape from inclusion in above roll, I have not had my share of compensatory post. operative trouble, the principal one being a two-year plague of diffuse, dense, iodine peritoneal adhesions, some of which caused intestinal obstruction, with three deaths. 'The abandonment of iodine skin disinfection and the return to old friends, alcohol mercurial lotion, and careful adjustment of isolating towels in and around parietal wounds by Mr. Marmaduke Sheild's through-and-through retractor silk sutures, relieved a situation which was really becoming intolerable.

It is not my desire to occupy space in reiteration of what I have already published on this subject, further than to mention that anyone may peruse my idees on the operation of gastro-enterostomy by referring to the Lancet, October $26 \mathrm{th}, 1912$, and it is possible that the method therein described may now merit some attention.

I think it a duty to repeat that in my opinion the employment of clamps in gastro enterostom y violates the rudi. ments of operative surgery, in that they entail a needless traumatic insult to the delicate visceral structures and a fatuous, if not culpable, obfuscation of potential haemorrhage from many important vessels which must be injured in tho course of the necessary incisions. I have no hesitation, judging from the number of fatalities whicli occur from post. operative haematemesis, in craving the attention of surgeons to what I maintain is a preventable catastrophe, and moreover, I consider it a disgrace to surgery and a parody on human reason that the term "haemostatic through-andthrough stitch" should ever have been countenanced in tho surgery of the stomach. I strongly recommend anyone who has not time or rerve openly to tackle the dozrn or so bleeding vessels which usually demand ligature before the insertion of the inver circular catgut suture to transfer such cases to a colleague gifted otherwise.

Reference to my paper "Operating to the clock" (British Medical Journal, December 21st, 1918) will probably remove the suspicion that I am of those who dis count the importance of time, yet I wish to emphasize that I am unable to follow the mentality that admits, in gastric surgery, of the repudiation of the cardinal rule-see the bleeding point and tie it.

With all deference I beg of the authors of operative textbooks to give these remarks some reflection, in the hope that they may see their way to delete some of the irons which now adorn their illustrations, and to bring a needle and thread into better perspective, with an artery forceps and ligature well in the foreground.

There is another item which has for years baffled my serse of comprehension-the inordinate haste to get these patients out of bed, and to mock their donbly lesioned stomachs by the early administration of solid food. The introduction of this-apart from direct and peristaltic traumatism, apart from the very negation of Hilton's law, and apart from the fact that it takes at least fourteen days for restitutio ad integrum of any solution of continuity in the human bodyis a physiological anachronism, in that it induces the gastric glands to pour forth an abundance of acid secretion at the moment when the organ is extra-handicapped with an addi. tional six-inch gastric sore, just when, by all the rules, an alkaline state is necessary for its salvation. Recently I was gratified to read that Dr. Moorhead, of Dublin, had called attention to this matter, and I hope his opinions will exact the consideration which they always deserve.

It has been my plan for many years, a few days after operation, to hand over these cases to the sister's personal care, with the injunction that they shall be kept in bed and 
on a rigid milk diet (in addition to mist. carbonatis, ter in die) until the twenty-eighth day. Before discharge each one recoives instructions as to what he should cat and drink during the ensuing year-invariably some alcoholic stimulant being recommended at lunch aud dinner.

It may not be reckoned irrelerant if I touch on the prophy. lactic treatment of this too prevalent malady, and in order to aroid prolixity, or getting out of deptl, I will briefly mention "ten commandments" which I have found of great scrvice to candidates for gastric ulcer who perforce have to else out a sedentary existence, with comparatively little out-door exercise.

1. As a general rule indulge only in two meals a day, and take only two plates to each ineal-meat with vegetables, and fi'uit, with or without light milk pudding, or cheese.

2. Masticate thoroughly, have any bad "sturnps" extracted.

3. Take, in moderation, whatever alcolıolic beverage is most congenial to your stomach-that is to say, which does not, hours afterwards, create excessive acidity or a feeling of " liver."

4. Whenever practicable, rest mind and body for one hour after a meat luuch in order to allow the digestive machine to get ready before an extra call for blood is made by brain or inuscles.

5. Allow at least a six-hour interval between miclday and evening meals.

6. Do not pollute the refreshing cup of afternoon tea ivith bread-and-butter, cakes, scones, or other decomposing fermenting carbohydrate messes, which deprive the nufortunate stomach of all cliance of a rest before it has to tackle its dinner problem.

7. Abjure the use of any form of alcoholic refieshment except at your lunch and dinner table.

8. Whenever feasible take a stroll in the evening after dinner, and sleep in a room with a large open wiudow-no in a draught-so that the blood may be properly oxygenated during the eight hours of repose.

9. Make it a creed to talke regular morning exercise : begin with a hard suap of shadow-boxing (commence with twenty and work gradually up to 100 double clouts) in order to cxtend the heait inuscle and elastic tissue of the lungs follow with physical exercises, then have a cold shower bath, and promptly conclude with towel drill before some open door or window.

10. Dulce est desipere in loco, but not too often.

I. am aware that I tread on delicate ground in adrocating the general moderate use of alcolsolic drink with meals. I do so, not inflated witis any exalted idea of preparing any medium for the gradual evolution to a future conception of some incomprehensible super-race, but to endeavour to make the best and most agreeable of what we are, and to lubricate the cranking gear of life through its chequered and allotted span by applying the lessons derived from lhirty years' experience in medical practice.

In response to the "Hillelujah" cantations of ascetic mummer's whose psycholcgical diapason is solely comprised of one hyphenated falsetto-to eradicate an abuse it is necessary to lop off the use-1 liave no compunction in affirming that the rational dietelic use of the formented juice of the grape, of the hop, and of some ccreals, is a godsend to man's digestion, and that while the indiscriminate use or bestial abuse of the same unquestionably speeds down to the grave, universal total abstentiou would tend, in a comparatively short cycle of time, to depopulate the earth, and, in all probability, would compel whatever might remain with human form ultimately to seek refuge in the simian freedom of an arboreal existence.

'The die is cast and the test is now being applied on a largo scale: may I beg my readers and their descendants carcfully to note and compare, in the respective wet and dry zoncs, the future incidence of tuberculosis, cancer, lunacy, diabetes, resistance to infection, addiction to the drug liabit, and frequent and prolonged tours abroad for business, icalth, and pleasure purposes?

A CoMmitTeE appointed to consider a suitable memorial for the so'diers of Madison County, New York, has recom mended the erection of a tuberculosis hospital to be maintained, under the provisions of the State county law, at the cxpense of the county.

DURING 1921, according to the New York Mledical Record, medical practitioners in New York State issued a total of 946,700 prescriptions for alcohol, th the Chicago district the number was $2,189,000$.

\section{fttemoranda:}

\section{MEDICAL, SURGICAL, OBSTETRICAL.}

BLINDNESS FOLLOWING INFLUENZA.

InTo my consulting-room in South Africa some years ago was led by two friends a man who was said to be blind. He had had influenza. Examination showed only a low degree of hypermetropic refractive error. Deciding there was nothing to prevent the patient seeing, I put up his correction and told him to read the letters on a board which was opposite him. This he promptly did, to his delight and to the mystification of his friends. I told him he did not need any glasses as he was an outdoor worker. He walked out of my room unassisted. Presumably the blurring-which a low error of hypermetropia will produce-liad been exaggerated by the weakness of the ciliary muscle resulting from influenza. That he thought he was blind was obvious. Not only was he led into my room, but he was actually on his way to book his passage to England to see an eye specialist.

Kilnhurst, nr. Rotherham. Charles J. Hill Aitken, M.D.

\section{DUODENAL ULCER IN A NEWBORN INFANT.}

ON February 9 th $I$ attended a Mrs. $X$. in her second confine. ment, after an interval of six years. After a normal labour she was delivered of a healthy female child, weighing just under $8 \mathrm{lb}$. Respiration was not well established at first, but after a few minutes the child breathed well and was a healthy colour. 'The first fourteen hours of life wore un eventful, and the child appeared to ve normal in every respect. There was then sudden haemorrhage from the mouth and the passage of somewhat dark blood per rectim. Calcium lactate with 1 minim of a 1 in 1,000 adrenaline chloride solution was given by the wouth, and rectal salines ( 1 oz. every hour) administered. For several hours the child appeared to improve, but twenty-eight hours after birth she died after a profuse haematemesis and melaena.

I was fortunately able to get the consent of the father for a post-mortem examination. The stomach was full of b!ood clot, but healthy. About half an inch from the pylorus there was a small duodenal ulcer rather less than half the size of a threepenny-piece. The duodenum was full of blood clot. There was no history of haemophilia or syphilis.

I unfortunately did not preserve the specimen, as at the time of the post-morlem examination $I$ did not think of publishing the case.

Braintree.

H. G. K. Young.

\section{CASE OF TRYPANOSOMIASIS FROM IVEST AFRICA} CURED BY ANTIMONY.

So much has been said and written about special methods of treatment and cures of trypanosomiasis by serum therapy and so-called specific drugs that it seems justifiable to bring forward a case of my own to add to those qnoted by Low and Newham, whici were under the care of Manson and Daniels.

The patient served in the British Expeditionary Force in the Cameroons in 1915; while there he contracted malaria quartan and subtertian, Filaria loa, with its embryonic form F. diurna, and Trypanosoma gainbiense. After many adventures he reached England, and came under my care in the Dreadnought Hospital from February to November, 1916. At one time trypanosomes were very abundant $(4,000$ per cubic millimetre), with cyclical outbursts, the general condition being bad. Atoxyl controlled but did not eradicate the iufection. Under intravenous injection of untimony oxide $1 / 2$ grain the blood was rapidly cleared. For a year he was under constant supervision in the laboratory at Greenwich, where treatment was continued. In May, 1917, he was again admitted into hospital for a further course of antimony, as there was a definite relapse, which rapidly cleaied up. A single trypanosome was found in 1918, but none since; films have been examined monthly. He lad a course of ten in. jections each spring in 1918, 1919, and 1920, of $1 / 2$ to 2 grains of antimony tartrate. This patient is now (1922) doing work, and is well but for the Calabar swellings; lie has filaria in his blood and a high eosinophilia. The strain of $T$.gambiense is being maintained in guinea-pigs, and has reached tho sixteenth passage.

The case may now be clainied as a severe infection of $T$. gambiensc cured by repeated injections of antimony London, W. 